\title{
Sistemas ambientais e vulnerabilidade à degradação dos recursos naturais dos municípios do Baixo Jaguaribe com aplicação de geotecnologia: subsídio ao ordenamento territorial*
}

\section{Huáscar Pinto Vidal de Oliveira', Edson Vicente da Silva ${ }^{2}$}

${ }^{1}$ Doutorando em Desenvolvimento e Meio Ambiente. Universidade Federal do Ceará. 2Departamento de Geografia. Universidade Federal do Ceará. E-mail: cacauceara@gmail.com.

Resumo. A delimitação dos sistemas ambientais e sua vulnerabilidade à degradação permitem um diagnóstico socioambiental perante as diversas pressões exercidas sobre um território. Contribui-se dessa forma ao ordenamento territorial, possibilitando identificar locais onde essas pressões exercidas têm potencial para causar uma maior degradação ambiental. Por isso a presente pesquisa objetiva-se analisar os sistemas ambientais, sua vulnerabilidade à degradação em face ao uso da terra, nos municípios do Baixo Jaguaribe do Estado do Ceará, através de técnicas de geotecnologias. Partiu-se dos estudos sistêmicos e integrador dos conhecimentos, que viabilizou as análises de inter-relações de causa e efeito, definindo a sensibilidade e a resistência do ambiente em face ao uso da terra. Dos resultados obtidos, observou-se de forma geral, que dentre os seis sistemas ambientais delimitados para o Baixo Jaguaribe, a planície litorânea foi o sistema ambiental mais instável com vulnerabilidade alta à ocupação, abrangendo mais da metade de toda a área, enquanto que o sistema ambiental dos tabuleiros prélitorâneos apresentou-se estável em condições de equilíbrio natural com vulnerabilidade baixa à ocupação demonstrando potencialidade para a expansão urbana. Destaca-se, não obstante, que há necessidade de continuidade das pesquisas o que permitirá resultados mais profícuos na realização do ordenamento territorial.

Palavras-chaves: Geoecologia; Susceptibilidade à degradação; Planejamento; Geoprocessamento.

Abstract. Environmental systems and vulnerability to degradation of natural resources of the municipalities in the Baixo Jaguaribe with application of geotechnology: subsidy to regional planning. The demarcation of the environmental systems and their vulnerability to degradation allow a socio-environmental diagnosis before the various pressures on a territory. It contributes to this way to spatial planning, allowing identify where such pressures have the potential to cause further environmental degradation. Therefore this objective is research to analyze the environmental systems, their vulnerability to degradation in the face of land use in the municipalities of the Baixo

Recebido:

29/07/2016

Aceito:

02/09/2016

Publicado:

30/09/2016

Acesso Aberto Artigo completo

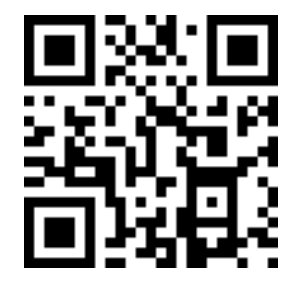

ORCID

(1) 0000-0002-4635-7932 Huáscar Pinto Vidal de Oliveira

(1) 0000-0001-5688-750X Edson Vicente da Silva

*Apresentado no V Congresso Brasileiro de Educação Ambiental Aplicada e Gestão Territorial, Fortaleza/CE, 8 a 11/06/2016. 
Jaguaribe (State of Ceará) through geotechnologies techniques. Left up systemic and integrative studies of knowledge, which enabled the analysis of interrelations of cause and effect, setting the sensitivity and environmental resilience in the face of land use. From the results, it was observed in general, that among the six environmental systems defined for the Baixo Jaguaribe, the coastal plain was the most unstable environmental system with high vulnerability to occupation, covering more than half of the entire area, while the environmental system of the pre-coastal trays remained stable natural equilibrium conditions with low vulnerability to the occupation demonstrating potential for urban expansion. It is noteworthy that despite no need for continuity of research which will allow more fruitful results in the realization of spatial planning.

Keywords: Geoecology; Susceptibility to degradation; Planning; GIS.

\section{Introdução}

Nos últimos anos, as geotecnologias adquiriram caráter fundamental para as pesquisas e monitoramentos ambientais, possibilitando maior eficiência com relação à obtenção e tratamento da elevada quantidade de dados e informações sobre recursos naturais e meio ambiente. Essas tecnologias geram inúmeras possibilidades de desenvolvimento dos sistemas de gestão e de monitoramento territorial, capazes de fornecer subsídios às demandas de sustentabilidade socioambiental (Batistella e Moran, 2008).

Pode-se afirmar que o ordenamento territorial está intimamente ligado ao processo participativo e integrado do desenvolvimento, com vistas a organizar o uso racional dos recursos naturais, considerando as formas de uso e ocupação local. Considera-se também as demandas sociais e a sustentabilidade dessas áreas. Esse modelo de política deve levar em conta, prioritariamente, os direitos coletivos das populações tradicionais, a conservação ambiental e a gestão sustentável dos recursos naturais. Para tanto, deve ser trabalhado de forma integrada e alinhada, com o que há de mais atual e em consonância com uma visão sistêmica e holística entre o desenvolvimento e o meio ambiente. Visa-se, em essência, ao ordenamento territorial para o alcance dos propósitos do desenvolvimento sustentável (Souza e Oliveira, 2011).

O território é um espaço onde se gera trabalho, onde se produz energia e informação, onde se revelam relações de poder. Fazer o diagnóstico de um recorte geográfico, portanto, é reconhecer suas configurações físicas, sociais e econômicas. Dessa forma, todo processo de gestão territorial, busca conciliar o desenvolvimento econômico com o ambiental, envolvendo planejamento do uso e da gestão dos recursos naturais. Dessa forma a delimitação dos sistemas naturais e sua ecodinâmica fazem-se necessariamente importante e prioritário.

O propósito de se desenvolver o tema proposto decorre de fatores específicos da área em foco (Baixo Jaguaribe) dentre os quais, podem-se destacar como componentes principais os seguintes: $\mathrm{O}$ histórico relacionado aos aspectos de uso e ocupação através da importância histórico-econômica do Vale do Rio Jaguaribe para o Estado do Ceará como um todo, pois o mesmo está ligado ao processo de ocupação do interior através da pecuária e do algodão e mais recentemente, através da implantação de inovações tecnológicas associadas à agropecuária. A complexidade dos arranjos da economia em detrimento dos constituintes ambientais, fazendo-se necessário um estudo alinhado com o que há de mais atual e em consonância com uma visão holística e 
sistêmica das relações da natureza com a sociedade; uso de interpretações tecnológicas e geoespaciais do momento (geotecnologias) para que se estabeleça um parâmetro de comparação entre os municípios, levando-se em conta os princípios de sustentabilidades.

Os problemas relacionados ao futuro do meio ambiente é conseqüência de várias transformações que marcaram a segunda metade do século XX, evoluindo de forma considerável nas últimas décadas. Para Bellen (2006) a relação sociedade e meio ambiente é um tema pouco abordado nas discussões iniciais. Subsequentemente, passou a ser considerada de forma mais crítica, globalizada e menos localizada devido ao fluxo de capital que se tornou intenso após a globalização da economia.

Ao longo do seu desenvolvimento econômico, o Estado do Ceará tem mantido um perfil econômico voltado para a agropecuária. A construção de sua economia foi baseada no binômio gadoalgodão. Nas últimas décadas a gestão estadual tem aproveitado as potencialidades naturais favoráveis ao ambiente do território para desenvolver metas que demonstram uma tendência forte para a dinamização do seu perfil econômico, através de atividades que favoreçam a expansão do capital no Estado bem como, se inserir no novo modelo econômico galgado nos últimos tempos em face do processo de globalização que, facilita a integração de economias e setores.

Devido à própria dinâmica de ocupação histórica do litoral brasileiro, as regiões litorâneas sofreram um processo de valorização, ocupação intensa e desordenada associada ao processo de globalização da economia. O Estado do Ceará tem sido objeto de adaptações e transformações que, se julgaram necessárias para a viabilização dos interesses do sistema capitalista mundial, não ficando de fora das transformações políticas ocorridas na década de 1980 que, favoreceram o incremento do setor. As atividades econômicas no Estado cresceram nas últimas décadas à medida que aumentou a cooperação entre os setores público e privado.
A Costa Leste do Estado do Ceará (Nordeste do Brasil) em especial os municípios litorâneos do Baixo Jaguaribe, têm sofrido uma grande pressão ocupacional em parte, devido a sua significativa disponibilidade hídrica, drenando uma área de $5.452 \mathrm{~km}^{2}$. Com a pressão exercida sobre a capacidade de uso daqueles recursos, traça-se um cenário que pode comprometer as possibilidades de uso dos recursos naturais. Isso pode ser motivado pelos anos de seca que comprometem a recarga das disponibilidades hídricas.

A gestão governamental aproveitou as potencialidades naturais do território e, vem, ao longo dos anos, desenvolvendo planos e metas que favorecem uma alteração do perfil econômico, através de atividades como a carcinicultura, piscicultura, turismo, comércio, entre outras. Nessa perspectiva, em virtude de que a faixa costeira do baixo Jaguaribe, ao longo dos anos, tornou-se um grande pólo de atrativo comercial referente às várias atividades, fez-se da área, alvo preferencial para a expansão urbana de forma desordenada e sem uma política eficaz de planejamento territorial. Ressalta-se, ainda que o dinamismo dessa região é impulsionado, de maneira específica, pela modernização da expansão agrícola, com a construção de novos perímetros irrigados nos Tabuleiros de Russas; pelo desenvolvimento de novas fontes de energia, pela expansão do comércio e dos serviços e pela implantação de indústria de grande porte e capital intensivo.

Do exposto anterior e buscando sistematizar a problemática do uso desordenado e, numa tentativa de melhor compreender as vulnerabilidades socioambientais dos sistemas naturais para subsidiar o ordenamento territorial, esta investigação tenta responder em que medida $\mathrm{o}$ ordenamento territorial seja possível ser mapeado e monitorado (avaliado) através de indicadores que transpareçam as condições socioambientais da área com aplicação adequada de geotecnologias a fim de estabelecer metas de sustentabilidade. É nesse contexto que o presente artigo se apresenta, a delimitar os 
sistemas naturais de forma a destacar as vulnerabilidades socioambientais para subsidiar o ordenamento territorial. Para validação da hipótese apresentada, usar-se-á como estudo os municípios do baixo Jaguaribe em que a aplicação de conceitos e técnicas investigativas aplicadas à delimitação dos ambientes naturais e à vulnerabilidade socioambiental em decorrência da grande pressão e transformações dos quais os mesmos são submetidos.

Destaca-se que, a partir desta análise com uso de geotecnologias em consonância com os preceitos de análise espaço-temporal auxilia na prevenção e mitigação dos impactos gerados pela forma de uso e ocupação do espaço territorial.

\section{Ordenamento territorial}

A noção do ordenamento territorial implica no entendimento de seu conceito que emerge dos estudos originados na Geografia francesa pós-revolução (aménagement du territoire) quando surge a necessidade de subdividir o território para fins de administração. (Michel, 1994).

No Brasil, o termo ordenamento territorial remonta aos anos 1980, quando foi concebido o Programa Nossa Natureza, desenvolvido pela Secretaria de Assessoramento da Defesa Nacional, subordinada ao Gabinete Militar da Presidência da República, para tratar de planos nacionais e regionais de ordenação do território e de desenvolvimento econômico social. Em 1988, tornou-se preceito constitucional e criado em 1990 a Secretaria de Assuntos Estratégicos (SAE), subordinada à Diretoria de Ordenação Territorial (DOT), que tinha como atribuições fazer cumprir o preceito constitucional. A estratégica básica da DOT, contudo, limitou-se à elaboração de Zoneamento Ecológico-Econômicos (ZEE), nos planos nacional, regional e estadual, que se constituem, certamente, em um dos principais instrumentos de ordenamento do território.

Em 1999, mediante a Medida Provisória $n^{0} 1.795 / 1999$, a SAE foi extinta e as suas atribuições referentes ao ZEE foram transferidas para o Ministério do Meio Ambiente, através da Medida Provisória $\mathrm{n}^{0}$ 1.911-8/1999. A partir de então, os ZEEs vêm sendo realizados de forma sistematizada e continuada, em parceria com os estados e diversos órgãos do Governo Federal.

Em 2003, decorridos mais de 15 anos da promulgação da Constituição Federal, foi marcado pela retomada de uma lógica territorial para o desenvolvimento do país, com a criação da Lei $n^{\circ} 10.683 / 2003$, que estabeleceu as atribuições de cada ministério, conferindo responsabilidades sobre o ordenamento territorial ao Ministério da Integração Nacional (MI) e ao Ministério da Defesa. Trataria de iniciar um processo de elaboração de uma Política Nacional de Ordenamento Territorial (PNOT) (Brasil, 2005).

A escala de atuação na concepção do PNOT deve ser a do território nacional, não obstante suas ações realizam-se em múltiplas escalas. Não se pode dessa forma, deixar de considerar as sub-regiões como uma escala espacial. Por isso, há necessidade de atuar em diferentes escalas espaciais e repensar o papel de cada instrumento de planejamento territorial, Peres e Chiquito (2012). O Zoneamento Ecológico-Econômico (ZEE) pode ser um instrumento chave de ordenamento territorial, mas deve ser integrado a outros instrumentos tal como a aplicação de indicadores de sustentabilidade socioambiental.

Desse modo, em 2004, o Ministério da Integração Nacional, fazendo valer o que determina a Constituição Federal, e em cumprimento às suas atribuições, decidiu elaborar uma proposta de Política Nacional de Ordenamento Territorial. Elaborou os Termos de Referência e procedeu a realização de processo licitatório para a contratação de serviços de consultoria para a realização dos estudos, que são apresentados neste documento.

Tradicionalmente, no Brasil, os instrumentos de política territorial trataram do crescimento econômico e da infraestrutura correlata, pois o ambiente construído das cidades era o objeto principal (Clementino, 2008). Apropriava- 
se do meio ambiente, independentemente das conseqüências sobre a natureza. A legislação brasileira que tem impacto sobre o ordenamento territorial também apresenta os mesmos vícios do planejamento nacional, no que respeita à incompatibilidade e à superposição de normas.

Destacando o ordenamento territorial como um dos instrumentos que concretiza o zoneamento ambiental, informações no âmbito socioambiental sobre a base territorial, subsidiará o sistema de planejamento. Esse planejamento deve orientar as iniciativas de investimentos governamentais e da sociedade, levando em conta as potencialidades e limitações da base dos recursos naturais (Souza et al., 2011).

Segundo Souza et al. (2011) para a proposta de ordenamento territorial, há que considerar alguns aspectos relevantes. Sob o ponto de vista conceitual e metodológico dois enfoques principais devem ser contemplados, o holístico e o sistêmico.

$\mathrm{O}$ holístico tendo em vista considerar todo o conjunto de componentes envolvidos na problemática do ordenamento territorial. $\mathrm{O}$ enfoque sistêmico deve ser adotado para que o ordenamento se faça em função das relações de interdependência entre a sociedade e a natureza. O mesmo constitui um instrumento indispensável na análise das interrelações de causa e efeitos, definindo a sensibilidade e resistência dos ambientes em face do processo de uso e ocupação (Souza et al., 2011).

Para a proposta de ordenamento territorial é de fundamental importância a compreensão das concepções analítica, sintética e dialética. A abordagem analítica identifica e caracteriza os componentes geoambientais e socioeconômicos; o sintético visa à caracterização dos arranjos espaciais dos sistemas ambientais e produtivos; o dialético para confrontar potencialidades e limitações de uso de cada sistema ambiental e os problemas advindos da apropriação dos bens naturais (Souza et al., 2011; Souza e Oliveira, 2011).

Com essa abordagem foram desenvolvidos diversos trabalhos, destacando-se os seguintes: Zoneamento Agroecológico do Nordeste, tratou-se do diagnós- tico do quadro natural e agrossocioeconômico. Foi elaborado pela EMBRAPA, em 1993, objetivando, essencialmente, subsidiar os órgãos de desenvolvimento na elaboração de propostas para o meio rural. A área de abrangência espacial foi 0 nordeste brasileiro, incluindo a porção setentrional de Minas Gerais. A região foi dividida em 20 unidades de paisagens, que agrupam 172 unidades geoambientais. As classes ou associações de solos foram consideradas como condicionantes fundamentais de delimitação das unidades geoambientais nas suas relações com os componentes climáticos, geomorfológicos e fito-ecológicos.

Como instrumento de planejamento, o zoneamento incorpora elementos fundamentais para a implementação de ações avaliadas como essenciais para o desenvolvimento tais como: aproveitamento racional dos resultados de pesquisas agronômicas pela implantação de testes de ajuste em áreas homogêneas; subsídios para locação de ações de reforma agrária, a partir do potencial em recursos naturais e das características da estrutura fundiária; orientação da política de crédito rural, de acordo com as condições edafoclimáticas; adequação das disponibilidades dos recursos hídricos superficiais e subsuperficiais à estrutura fundiária e aos sistemas de produção, dentre outras.

O Zoneamento Ecológico-Econômico do Bioma Caatinga e Serras Úmidas do Estado do Ceará (2006), adota o Programa de Zoneamento Ecológico-Econômico do Brasil (ZEE), concebido pelo Governo Federal desde a última década do século passado, preconizado como instrumento de ordenamento territorial e de redirecionamento de atividades. $\mathrm{O}$ trabalho resultou de convênio entre a SEMACE e a FCPC/UFC apontando como objetivos fundamentais a identificação de oportunidades de uso dos recursos naturais, estabelecendo parâmetros necessários de exploração e os impactos positivos e negativos; identificação e análise dos problemas ambientais como áreas degradadas por desmatamentos, perda ou degradação do solo e da água por práticas inadequadas de agricultura e pecuária, usos permissivos das 
águas superficiais e subterrâneas, exploração irregular da biodiversidade; avaliação de conflitos de interesse entre o uso dos recursos naturais e as políticas ambientais, bem como a concorrência de uso entre os segmentos sociais; definição do zoneamento como instrumento de planejamento que coleta, organiza dados e informações sobre o território propondo alternativas de preservação e/ou recuperação dos recursos naturais e a manutenção da qualidade ambiental. Configura-se por conseqüência, como instrumento essencial para a prática da concepção de desenvolvimento sustentável.

Para Borja e Uzeta (2007) o ordenamento territorial também corrobora com as abordagens dos autores brasileiros retromencionados, pois considera também um instrumento para se alcançar o processo de desenvolvimento sustentável em função de um equilíbrio induzido entre os recursos naturais, as atividades produtivas, as condições ambientais e os assentamentos humanos. Propõe para essa fase de desenvolvimento da pesquisa: 1 . Caracterização do sistema e subsistema natural, sua capacidade de suporte, ecodinâmica e vulnerabilidade; 2. Diagnóstico do sistema territorial, apontando o desenvolvimento de indicadores específicos para cada subsistema analisado; 3. Integração e síntese do diagnóstico com desenho de cenários de uso e aproveitamento do território. Em fase posterior buscar-se-á propor modelo de uso e aproveitamento do território que inclua a elaboração de estratégias políticas e metas básicas de um Programa de Ordenamento Territorial a médio e longo prazo.

Quanto à ecodinâmica, termo proposto pelo geógrafo francês Tricart (1977) utilizado para avaliar as condições de estabilidade/instabilidade dos ecossistemas e/ou geossistemas. Segundo esse autor, o componente mais importante da dinâmica da superfície da terra é o morfogênico que produz instabilidade e é um fator limitante muito importante no desenvolvimento dos seres vivos.

\section{Geotecnologias}

As Geotecnologias representam um conjunto de instrumentos, programas e procedimentos que abrangem aplicações diversas, no contexto dos sistemas de posicionamento orientados por satélites, dos bancos de dados geográficos, dos sistemas de informação geográfica e do sensóriamento remoto (Filippini Alba et al., 2009). Por outra parte, pode-se definir as geotecnologias como tecnologias que envolvem ou se aplicam a informações georreferenciadas, isto é, dados associados ao espaço físico, onde a análise espacial faz parte do processo.

A tecnologia "é a ciência dos meios", sendo assim a geotecnologia "é a arte e a técnica de estudar a superfície da terra e adaptar as informações às necessidades dos meios físicos, químicos e biológicos". O Processamento Digital de Imagens (PDI), a geoestatística e os SIGs fazem parte da geotecnologia (Silva, 2003). Não obstante, utilizar a geotecnologia pode significar a utilização de computadores como instrumentos de representação de dados espacialmente referenciados. Mas o problema fundamental consiste no estudo e na implementação de diferentes formas de representação computacional do espaço geográfico.

De acordo com Câmara et al. (2001), o geoprocessamento pode ser considerado uma tecnologia interdisciplinar, que permite a convergência de diferentes disciplinas científicas para 0 estudo de fenômenos ambientais e urbanos, mas podem esconder um problema conceitual: "redução dos conceitos de cada disciplina em algoritmos, estruturas de dados utilizados para armazenamento e tratamento dos dados geográficos" (Câmara et al., 2001, p. 7).

Os SIG pioneiros tiveram sucesso em captar como o mundo se parece, mas tiveram poucos resultados na maioria das questões envolvendo como o mundo funciona. Atualmente, existe uma ampla gama de aplicações do SIG, tais como 
mapeamento de base topográfica, modelagem socioeconômica e ambiental, modelagem global e ensino (Longley et al., 2013).

Anderson e Shimabukuro (2007), aplicando o SIG na análise das alterações dos sistemas terrestres no Estado do Mato Grosso por desflorestamento e por queimadas, utilizou o NDVI e EVI. Resultou em um valor médio anual de 0,86 para o NDVI e de 0,53 para o EVI, cujos valores resultaram altos em relação aos que são encontrados na literatura, pressupondo que a causa da diferença seja por dois componentes: a) intervalos das séries temporais utilizadas e b) características das imagens do sensor.

Do ponto de vista da sustentabilidade ambiental que permeia o desenvolvimento sustentável, a melhor forma de se trabalhar a gestão dos territórios é através de indicadores de sustentabilidade aliada ao conhecimento técnico capazes de medir o grau de desenvolvimento de uma determinada região.

Os indicadores são informações de caráter quantitativo resultantes do cruzamento de pelo menos duas variáveis primárias como informações espaciais, temporais e ambientais. Como ferramenta de auxílio à tomada de decisões, os indicadores são modelos simplificados da realidade com a capacidade de facilitar a compreensão dos fenômenos, aumentando capacidade de comunicação de dados brutos e adaptando informações de linguagem aos interesses locais (Magalhães Júnior, 2007).

Desse ponto de vista, tem-se observado que a importância das geotecnologias aliada às análises de indicadores de sustentabilidade são de fundamental importância nessa etapa de gestão. As mesmas constituem elementos importantes de análise, por armazenar e representar dados importantes com relação à temática. Assim, a coleta de informações sobre a gestão e distribuição geográfica dos recursos naturais e socioeconômicos sempre foi parte importante das atividades das sociedades organizadas. No entanto, essas informações eram disponibilizadas apenas em documentos e mapas de papeis, dificultando uma análise mais precisa desses dados. Com o desenvolvimento de tecnologias de informática na segunda metade do século XX tornou-se possível armazenar e representar dados em ambientes computacionais abrindo com isso, espaço para o aparecimento dos sistemas geotecnológicos (Câmara et al., 2001).

Os impactos causados pelo homem têm gerado níveis críticos de degradação ambiental em diversas áreas da superfície terrestre. Uma tendência fortemente verificada na atual sociedade, através do avanço tecnológico e das políticas de desenvolvimento, é a crescente evolução dos processos de transformação das paisagens naturais em paisagens artificializadas que modificam os ciclos de matéria, fluxos de energia e biodiversidade. Além de causar grandes prejuízos aos recursos naturais, como supressão indiscriminada das florestas tropicais e assoreamento e contaminação de recursos hídricos (a exemplo da área proposta no estudo) vem colocando o ambiente como objeto de estudo em diversas áreas do conhecimento (Batistella e Moran, 2008).

Nos últimos anos, as geotecnologias adquiriram caráter fundamental para pesquisas e monitoramentos ambientais devido ao fato de possibilitarem uma maior eficiência com relação à obtenção de tratamento de elevada quantidade de dados e informações sobre recursos naturais. Esse tipo de tecnologia gera inúmeras possibilidades de desenvolvimento do sistema de gestão e de monitoramento territorial, capazes de fornecer subsídios às demandas de sustentabilidade socioambiental (Batistella e Moran, 2008).

Vários autores trabalharam a visão de ordenamento territorial e desenvolvimento sustentável aliada às geotecnologias, dentre eles pode-se citar Câmara e Davis (2000), Silva e Zaidan (2004), Venturi (2005), Magalhães Junior (2007), Morgado e Rocha (2008), Batistella e Moran (2008), Oliveira (2009), Bacani (2010) e Fitz (2008). Ressalta que, para se trabalhar geotecnologia torna-se necessário a compreensão de determinadas técnicas específicas. Uma delas se refere ao uso de bases cartográficas confiáveis, vinculadas à compreensão de regras básicas para a 
representação da realidade. Desse modo, a aplicação de geotecnologias como ferramentas de sistematização e geração de conhecimento auxiliam no planejamento do uso da terra, elevando a eficiência da gestão territorial e fazendo desse campo, um espaço muito amplo no que tange aos trabalhos desenvolvidos para a gestão e monitoramento ambiental. A construção de uma base de indicadores, a elaboração e manutenção de banco de dados geográficos e ambientais e gestão físico-territorial são exemplos dessas técnicas.

\section{Delimitação dos sistemas ambientais e sua vulnerabilidade à degradação da área de estudo}

O Baixo Jaguaribe localiza-se a nordeste do Estado do Ceará, prolongandose até a costa. A área do baixo Jaguaribe abrange 13 municípios: Fortim, Aracati, Icapuí, Itaiçaba, Palhano, Russas, Quixeré, Limoeiro do Norte, Morada Nova, Tabuleiro do Norte, São João do Jaguaribe, Alto Santo e Jaguaruana. Dos 13

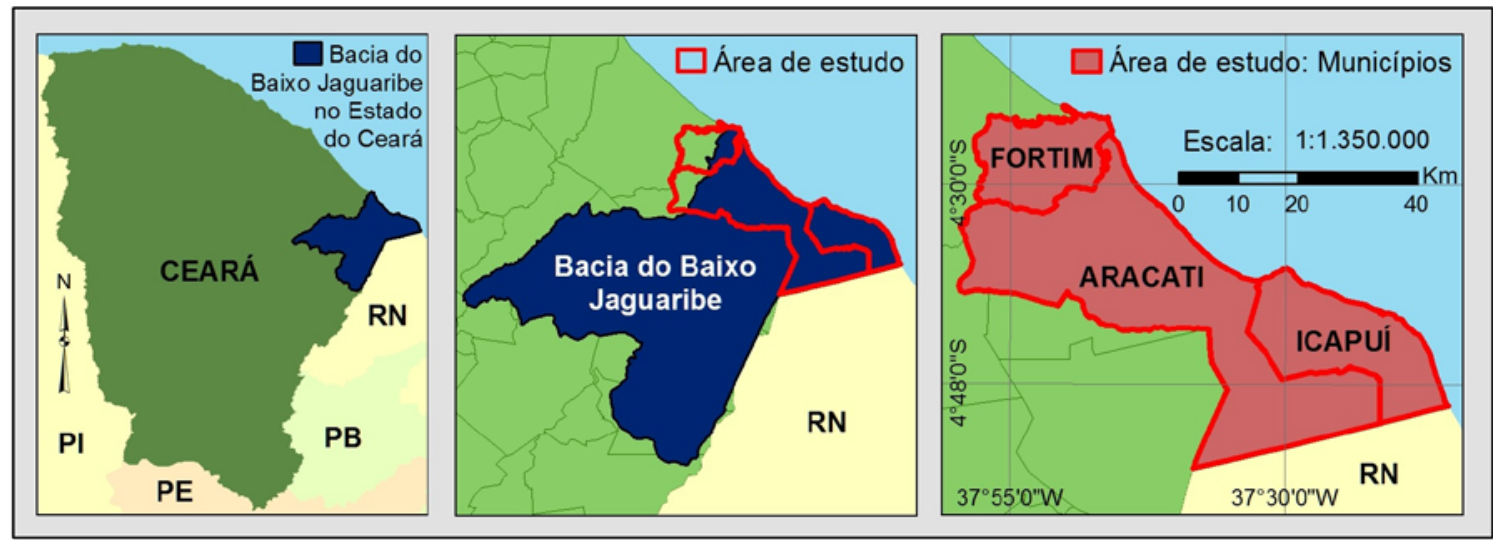

Figura 1. Cartograma de localização geográfica da área de estudo, correspondente aos municípios litorâneos (Aracati, Fortim e Icapuí) da Bacia Hidrográfica do Baixo Jaguaribe, Estado do Ceará.

municípios, apenas três (Fortim, Aracati e Icapuí) são objeto de estudo da pesquisa, por sua localização costeira.

De acordo com Rodriguez et al. (2004) as unidades ecológicas (ou geoambientais) entende-se a individualização, tipologia e unidades regionais e locais da paisagem. Essas unidades ecológicas ou sistemas ambientais quanto à sua vulnerabilidade tornou-se de grande relevância para estudos relacionados com a gestão ambiental e o ordenamento territorial. O estabelecimento da vulnerabilidade ambiental dos sistemas ambientais que compõe os municípios do baixo Jaguaribe partiu-se da metodologia estabelecida por Tricart (1977) e que serviu como âncora para metodologias voltadas à vulnerabilidade ambiental, como estabelecida por Souza (2000) e Souza e Oliveira (2011) e utilizada em estudos voltados para o planejamento tanto de áreas urbanas como de áreas rurais. O estudo da ecodinâmica dos ambientes relacionados ao uso e ocupação da terra é considerado como critério básico para a definição da maior ou menor susceptibilidade à degradação dos sistemas ambientais inseridos no Baixo Jaguaribe. Para Souza (2006, p. 121) com o acelerado processo de uso e ocupação e desenvolvimento das atividades socioeconômicas, há tendências ao aceleramento dos processos morfogenéticos, que influem diretamente nas condições de estabilidade ambiental. Esses acarretam uma série de consequências negativas, que produzem impactos ambientais emergentes, ocasionando o comprometimento da qualidade ambiental e reversão de ambientes estáveis em instáveis. A associação das causas naturais aos tipos de usos e ocupação que são exercidos no ambiente revela a situação 
atual dos sistemas ambientais face às suas condições de estabilidade/instabilidade.

Os sistemas ambientais foram delimitados considerando os critérios holísticos voltados para métodos e técnicas relacionados aos padrões com base em teorias geossistêmicas, ecodinâmica e análise multicritério das áreas de escopo ambiental.

Por tanto, dependendo das particularidades de cada sistema ambiental e sua maior ou menor dificuldade para identificação, caracterização e delimitação das mesmas, em nível de processamento digital de imagem (PDI), fez-se necessário o apoio de dados conjunto biofísicos (litoestratigrafia, geologia, geomorfologia, vegetação, entre outros, com base em determinada hierarquia de correlação de fatores em razão de fenômenos naturais em diferentes escalas, conjuntos ou específicos, definindo padrões característicos de cada sistema ambiental (ou unidade geoambiental).

Para o mapeamento detalhado em escala 1:100.000 dos sistemas e subsistemas ambientais foi utilizado as imagens de satélite Landsat-8, cena/ponto (216/063), com menos de $10 \%$ de nuvens, compondo as bandas (multiespectrais) 1,2 , $3,4,5,6,7,9$ de resolução espacial de 30 metros, banda (PAN) 8 de 15 m e resolução radiométrica de 16 bits. Aplicando as técnicas e ferramentas da geotecnologia, delimitou-se seis sistemas ambientais e 10 subsistemas.

Elaborou-se o mapeamento, Figura 2, preliminar dos sistemas e subsistemas ambientais com vista ao reconhecimento e ordenamento do território. Na Figura 3, demonstra-se os critérios técnicos em geotecnologias com base em padrões espectrais e metodologia de campo para reconhecimento e nível de confiança para delimitação dos sistemas e subsistemas ambientais. Com base na abordagem analítica descrita anteriormente sintetizouse nas Figuras $4,5,6,7,8$ e 9 as características naturais dominantes, capacidade de suporte, ecodinâmica e vulnerabilidade, impactos e riscos de ocupação, cenários tendenciais do contexto socioambiental de cada sistema e subsistema ambiental.

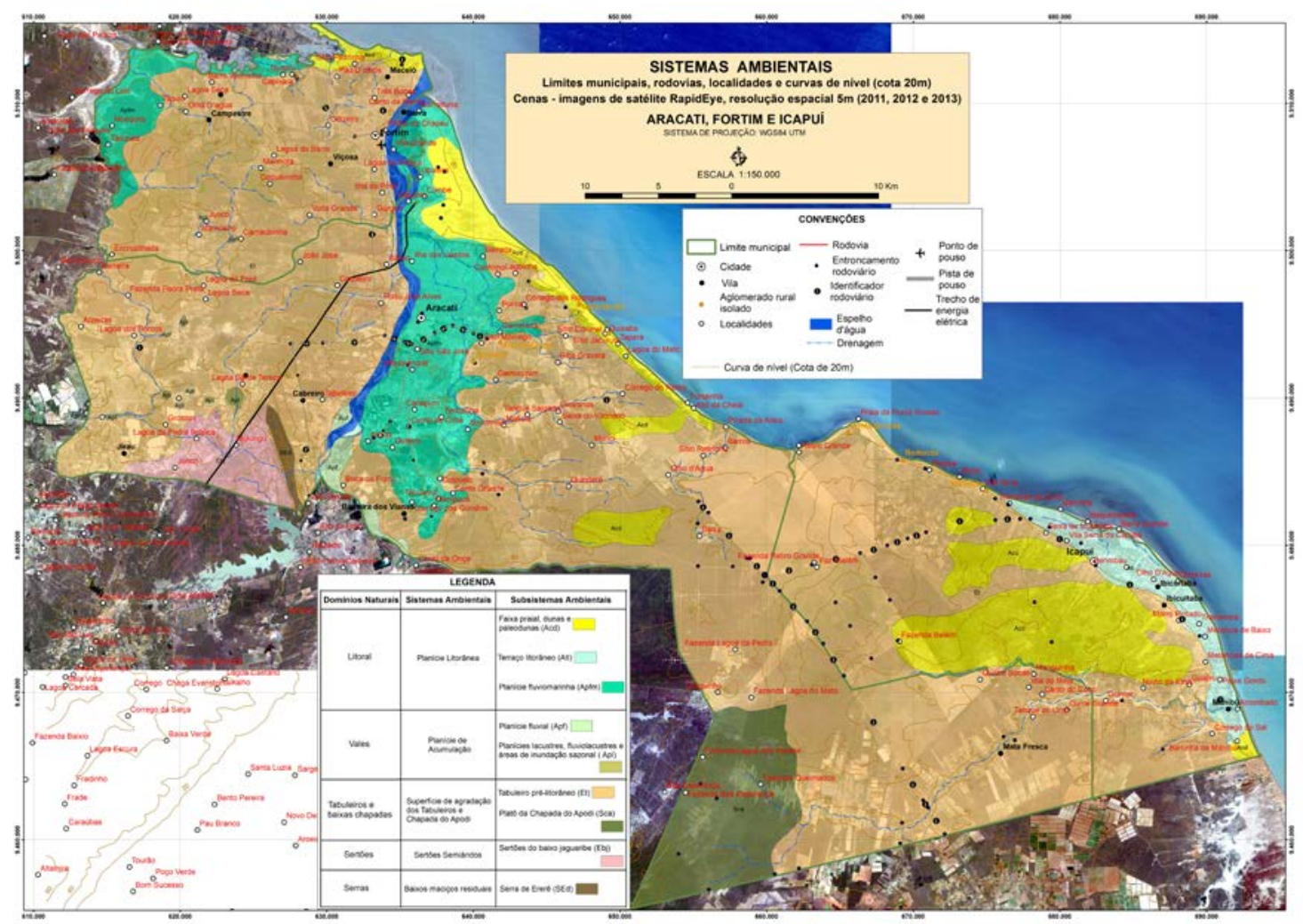

Figura 2. Mapa de sistemas e subsistemas ambientais. 


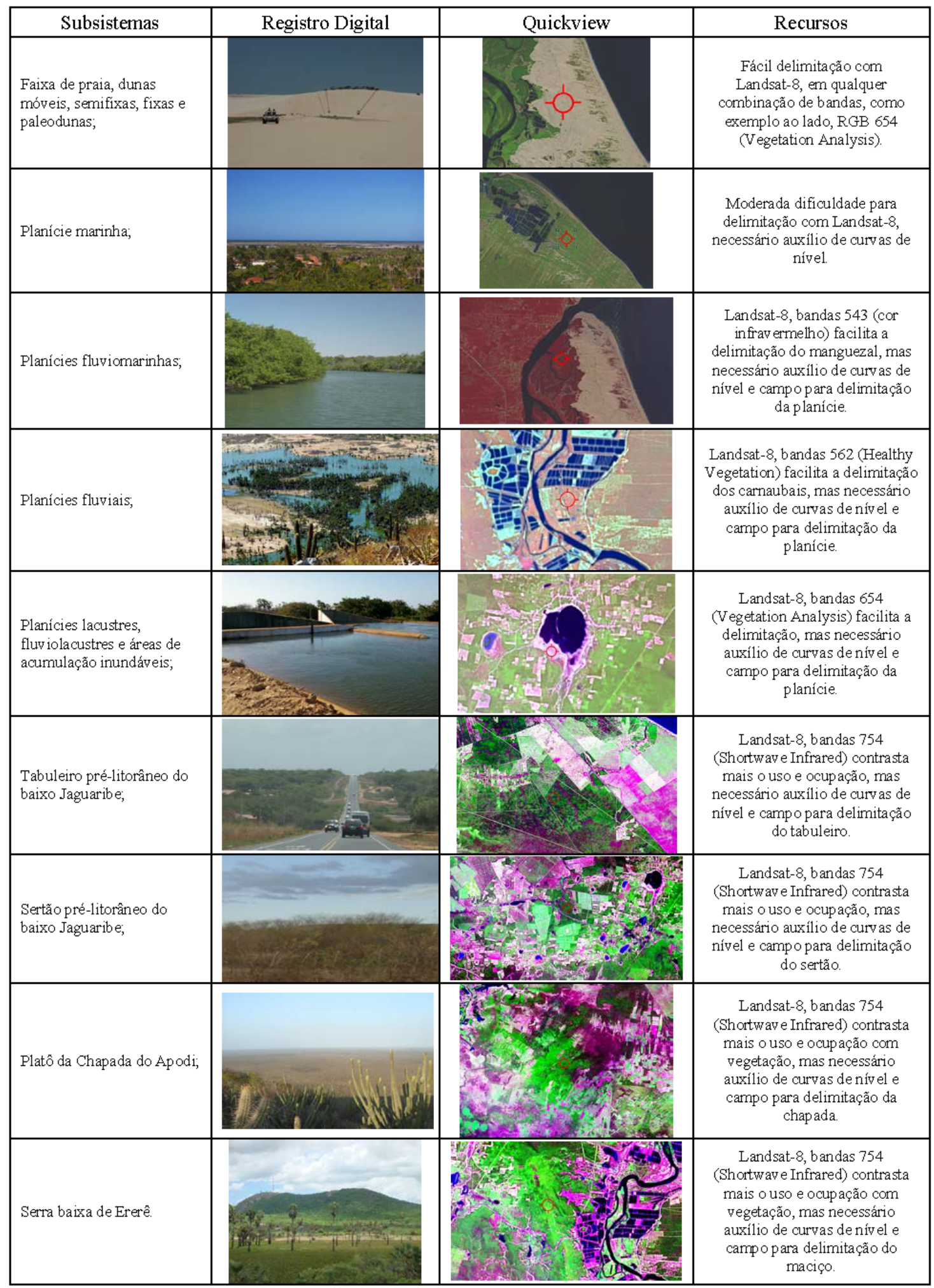

Figura 3. Respostas (padrões) espectrais das imagens Landsat-8 com base nas características técnicas do sensor para cada subsistema ambiental aliado ao levantamento em campo. 


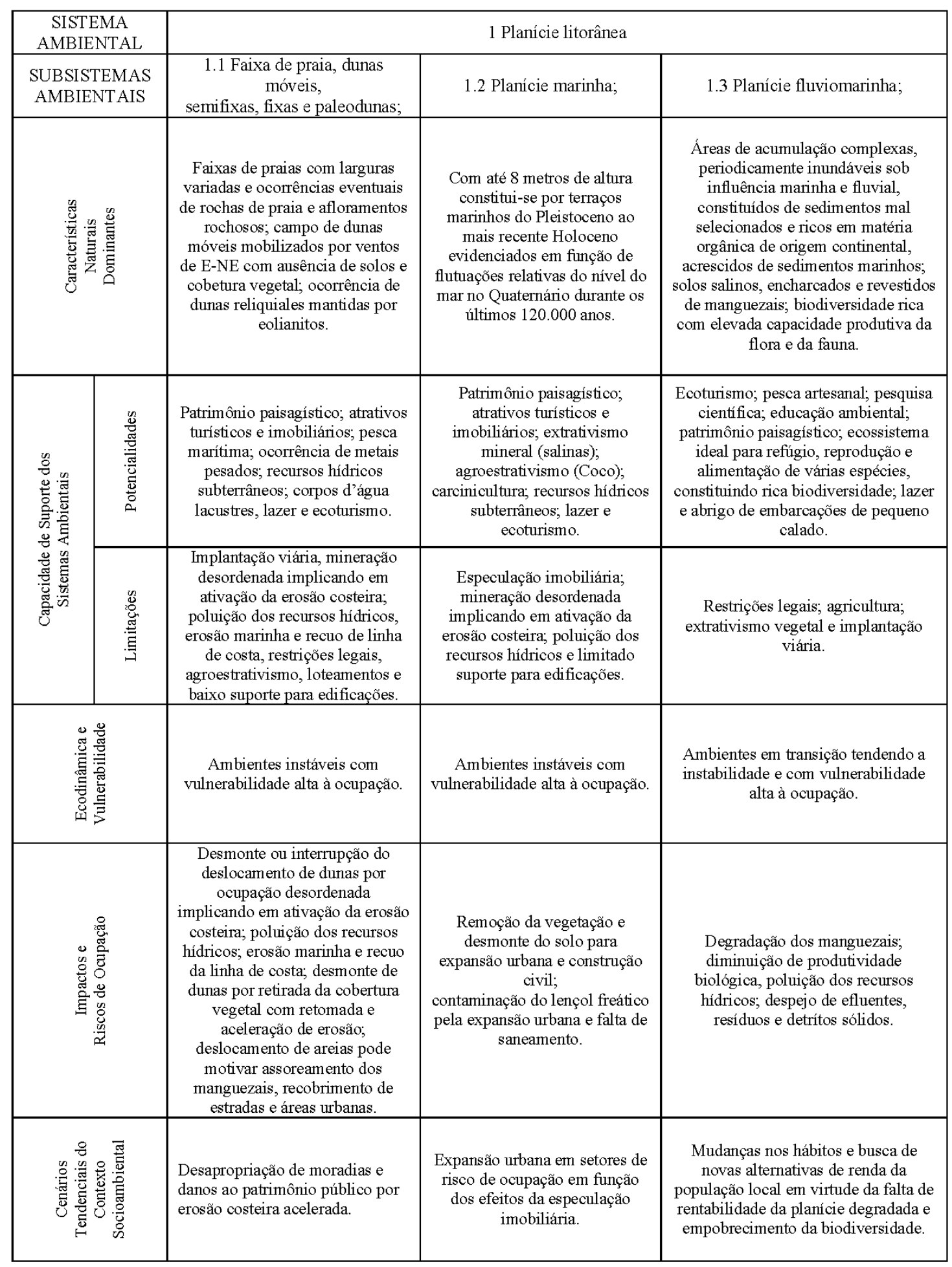

Figura 4. Sistema ambiental Planície Litorânea e subsistemas. Fonte: Adaptado de Souza (1994). 


\begin{tabular}{|c|c|c|c|}
\hline \multirow{2}{*}{\multicolumn{2}{|c|}{$\begin{array}{c}\text { SISTEMA } \\
\text { AMBIENTAL } \\
\text { SUBSISTEMAS } \\
\text { AMBIENTAIS }\end{array}$}} & \multicolumn{2}{|c|}{2 Planícies ribeirinhas } \\
\hline & & 2.1 Planícies fluviais; & $\begin{array}{l}\text { 2.2 Planícies lacustres, fluviolacustres e áreas de } \\
\text { acumulação inundáveis. }\end{array}$ \\
\hline \multicolumn{2}{|c|}{$\begin{array}{l}\text { Características } \\
\text { Naturais } \\
\text { Dominantes }\end{array}$} & $\begin{array}{l}\text { Faixas de acumulação aluvial dos Rios Jaguaribe e } \\
\text { Pirangi com dimensões proporcionais à capacidade de } \\
\text { escoamento, transporte e deposição das correntes } \\
\text { fluviais; superfícies baixas de várzeas parcialmente } \\
\text { inundáveis, revestidos por matas ribeirinhas que tem } \\
\text { maior frequência de carnaubais. }\end{array}$ & $\begin{array}{l}\text { Faixas de acumulação de sedimentos areno-argilosos, } \\
\text { moderadamente a mal selecionados, bordejando lagoas } \\
\text { de origem fluvial, freática ou mista, além de áreas de } \\
\text { acumulação inundáveis durante a estação chuvosa; } \\
\text { compõem-se de Planossolos, Neossolos Flúvicos } \\
\text { revestidos por matas ciliares de carcaúbas e gramineas. }\end{array}$ \\
\hline \multirow{2}{*}{ 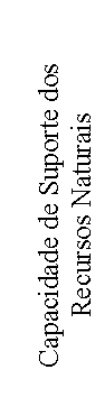 } & 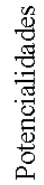 & $\begin{array}{l}\text { Agroextrativismo; recursos hídricos; agropecuária; } \\
\text { mineração controlada; agricultura irrigada; pesca } \\
\text { artesanal; atrativos turísticos e de lazer. }\end{array}$ & $\begin{array}{l}\text { Patrimônio paisagístico, ecoturismo, reservas hídricas } \\
\text { superficiais, pesca artesanal, mineração controlada } \\
\text { (cerâmicas, olarias), agroestrativismo, lazer, áreas de } \\
\text { pouso, refúgio e alimentação de aves migratórias. }\end{array}$ \\
\hline & 逽 & $\begin{array}{l}\text { Restrições legais; drenagem irregular dos solos; } \\
\text { salinização e inundações periódicas; mineração } \\
\text { descontrolada; expansão urbana nos baixos níveis de } \\
\text { terraços fluviais. }\end{array}$ & $\begin{array}{l}\text { Restrições legais, inundações períodicas, drenagem } \\
\text { dos solos e poluição dos recursos hídricos. }\end{array}$ \\
\hline \multicolumn{2}{|c|}{$\begin{array}{l}\text { Ecodinâmica e } \\
\text { Vulnerabilidade }\end{array}$} & $\begin{array}{l}\text { Ambientes de transição tendendo à estabilidade em } \\
\text { condições de equilibrio natural; vulnerabilidade } \\
\text { moderada à ocupação. }\end{array}$ & $\begin{array}{l}\text { Ambientes estáveis quando em equilíbrio natural e } \\
\text { poucos impactos pelo atropismo; vulnerabilidade } \\
\text { moderada à ocupação. }\end{array}$ \\
\hline \multicolumn{2}{|c|}{$\begin{array}{l}\text { Impactos e } \\
\text { Riscos de } \\
\text { Ocupação }\end{array}$} & $\begin{array}{l}\text { Degradação de mata ciliar desencadeando processos } \\
\text { erosivos e assoreamento dos rios; poluição dos recursos } \\
\text { hídricos; salinização dos solos; inundações e cheias. }\end{array}$ & $\begin{array}{l}\text { Degradação da mata ciliar, mineração descontrolada, } \\
\text { despejo de efluentes e detritos sólidos; poluição dos } \\
\text { solos e dos recursos hídricos. }\end{array}$ \\
\hline \multicolumn{2}{|c|}{$\begin{array}{l}\text { Cenários } \\
\text { Tendenciais do } \\
\text { Contexto } \\
\text { Socioambiental }\end{array}$} & $\begin{array}{l}\text { Prejuízos socioeconômicos e impactos ambientais com } \\
\text { inundações e cheias, durante períodos chuvosos, em } \\
\text { áreas com advento de expansão urbana desordenada. }\end{array}$ & $\begin{array}{l}\text { Prejuizos para a pesca artesanal e impactos } \\
\text { ambientais por ocupação e atividades inadequadas e } \\
\text { antrópicas. }\end{array}$ \\
\hline
\end{tabular}

Figura 5. Sistema ambiental Planícies ribeirinhas e subsistemas. Fonte: Adaptado de Souza (1994). 


\begin{tabular}{|c|c|c|}
\hline \multicolumn{2}{|c|}{ SISTEMA AMBIENTAL } & 3 Tabuleiro pré-litorâneo \\
\hline \multicolumn{2}{|c|}{$\begin{array}{l}\text { SUBSISTEMAS } \\
\text { AMBIENTAIS }\end{array}$} & 3.1 Tabuleiros pré-litorâneos do baixo Jaguaribe; \\
\hline \multicolumn{2}{|c|}{$\begin{array}{l}\text { Características } \\
\text { Naturais } \\
\text { Dominantes }\end{array}$} & $\begin{array}{l}\text { Grupo Barreiras (Indiviso), sedimentos cenozóicos, arenitos argilosos de tonalidade variegada. } \\
\text { Superficie com caimento topográfico suave na direção da linha de costa, com declive inferior a } 5 \% \text {. } \\
\text { Situados à retaguarda e por baixo do cordão de dunas gradando sem ruptura topográfica para os } \\
\text { sedimentos que compõem da Bacia Potiguar ou da depressão sertaneja. }\end{array}$ \\
\hline \multirow{2}{*}{ 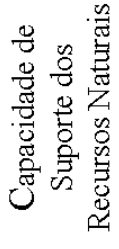 } & Potencialidades & $\begin{array}{l}\text { Expansão urbana; agroextrativismo; mineração; agricultura irrigada; instalação viária; materiais de } \\
\text { construção civil; ecoturismo; águas subterrâneas; cultivo de côco e cajú }\end{array}$ \\
\hline & Limitações & $\begin{array}{l}\text { Baixa fertilidade dos solos; carência de locais favoráveis para represamento; irregularidade } \\
\text { pluviométrica. }\end{array}$ \\
\hline \multicolumn{2}{|c|}{$\begin{array}{l}\text { Ecodinâmica e } \\
\text { Vulnerabilidade }\end{array}$} & $\begin{array}{l}\text { Ambiente estável em condições de equilíbrio natural; } \\
\text { vulnerabilidade baixa à ocupação. }\end{array}$ \\
\hline \multicolumn{2}{|c|}{$\begin{array}{l}\text { Impactos e } \\
\text { Riscos de Ocupação }\end{array}$} & $\begin{array}{l}\text { Desencadeamento de processos erosivos em áreas desmatadas; riscos de poluição dos recursos } \\
\text { hídricos subterrâneos; expansão urbana desordenada e impermeabilização do solo comprometendo } \\
\text { recarga hídrica. }\end{array}$ \\
\hline \multicolumn{2}{|c|}{$\begin{array}{l}\text { Cenários Tendenciais do } \\
\text { Contexto } \\
\text { Socioambiental } \\
\end{array}$} & $\begin{array}{l}\text { Comprometimento do acesso aos recursos hídrico com poluição, redução e esgotamento das } \\
\text { reservas aquíferas subterrâneas em decorrência de expansão urbana desordenada, falta de } \\
\text { saneamento e poços clandestinos. }\end{array}$ \\
\hline
\end{tabular}

Figura 6. Sistema ambiental Tabuleiro pré-litorâneo e subsistema. Fonte: Adaptado de Souza (1994).

\begin{tabular}{|c|c|c|}
\hline \multicolumn{2}{|c|}{ SISTEMA AMBIENTAL } & 4 Depressão Sertaneja \\
\hline \multicolumn{2}{|c|}{$\begin{array}{l}\text { SUBSISTEMAS } \\
\text { AMBIENTAIS } \\
\end{array}$} & 4.1 Sertão pré-litorâneo do Baixo Jaguaribe; \\
\hline \multicolumn{2}{|c|}{$\begin{array}{l}\text { Características } \\
\text { Naturais } \\
\text { Dominantes }\end{array}$} & $\begin{array}{c}\text { Litotipos do Grupo Orós, Formação Santarém (micaxistos diversos); superficie pediplanada a } \\
\text { parcialmente dissecada em largos interflúvios tabulares cristalinos de Complexo Nordestino; } \\
\text { Planossolo Solódico associado a Neossolos Litólicos Eutróficos e Argissolos Vermelho-Amarelo } \\
\text { Eutrófico; }\end{array}$ \\
\hline \multirow{2}{*}{ 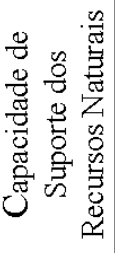 } & Potencialidades & Agropecuária; mineração (argilas); potencial hídrico de superficie e sub-superficie (aluviões). \\
\hline & Limitações & Deficiência hídrica na estiagem; encharcamentos temporários dos solos de baixada. \\
\hline \multicolumn{2}{|c|}{$\begin{array}{l}\text { Ecodinâmica e } \\
\text { Vulnerabilidade }\end{array}$} & $\begin{array}{l}\text { Ambiente estável quando em equilíbrio natural e com vulnerabilidade moderada a baixa à } \\
\text { ocupação. }\end{array}$ \\
\hline \multicolumn{2}{|c|}{$\begin{array}{c}\text { Impactos e } \\
\text { Riscos de Ocupação }\end{array}$} & Extrativismo mineral de argilas e de areias aluvionares sem prática adequadas. \\
\hline \multicolumn{2}{|c|}{$\begin{array}{l}\text { Cenários Tendenciais do } \\
\text { Contexto } \\
\text { Socioambiental }\end{array}$} & $\begin{array}{l}\text { Extrativismo mineral e vegetal indiscriminado e degradação ambiental, aceleração dos processos } \\
\text { erosivos, diminuição da disponibilidade de águas superficiais e estiagem mais severa, busca de } \\
\text { renda das familias em outras áreas mais distantes e/ou buscam obter bolsa família, procura de novas } \\
\text { alternativas de renda ou migração. }\end{array}$ \\
\hline
\end{tabular}

Figura 7. Sistema ambiental da Depressão Sertaneja Fonte: Adaptado de Souza (1994). 


\begin{tabular}{|c|c|c|}
\hline \multicolumn{2}{|c|}{ SISTEMA AMBIENTAL } & 5 Chapada sedimentar \\
\hline \multicolumn{2}{|c|}{$\begin{array}{l}\text { SUBSISTEMAS } \\
\text { AMBIENTAIS }\end{array}$} & 5.1 Platô da Chapada do Apodi; \\
\hline \multicolumn{2}{|c|}{$\begin{array}{l}\text { Características } \\
\text { Naturais } \\
\text { Dominantes }\end{array}$} & $\begin{array}{c}\text { Superficie plana coincidente com a estrutura geológica trabalhada por pediplanação e limitada por } \\
\text { escarpas erosivas em rochas calcárias da Formação Jandaíra, drenagem muito rarefeita e } \\
\text { escoamento intermitente sazonal. A Formação Jandaíra, no topo do Grupo Apodi, forma uma } \\
\text { pequena cornija responsável pelo desnível de cerca de } 6 \text { a } 10 \mathrm{~m} \text { com arenitos da Formação Açu. } \\
\text { Com Solos Cambissolos, de boa fertilidade, conferindo uma predominancia de caatinga arbórea } \\
\text { arbustiva moderadamente degradada. }\end{array}$ \\
\hline \multirow{2}{*}{ 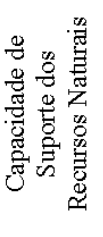 } & Potencialidades & $\begin{array}{l}\text { Alta fertilidade natural dos solos; topografias favoráveis; bom potencial de águas subterrâneas; e } \\
\text { boa filtragem; jazidas de cancário sedimentar. }\end{array}$ \\
\hline & Limitações & $\begin{array}{c}\text { Baixo potencial de águas superficiais; limitações quanto à regarca e captação de água; grande } \\
\text { profundidade do lençol freático, pluviometria baixa e irregular, inexistência de locais propícios a } \\
\text { barramentos de rios. }\end{array}$ \\
\hline \multicolumn{2}{|c|}{$\begin{array}{l}\text { Ecodinâmica e } \\
\text { Vulnerabilidade }\end{array}$} & $\begin{array}{l}\text { Ambiente estável em condições de equilíbrio natural; } \\
\text { vulnerabilidade baixa à ocupação. }\end{array}$ \\
\hline \multicolumn{2}{|c|}{$\begin{array}{l}\text { Impactos e } \\
\text { Riscos de Ocupação }\end{array}$} & $\begin{array}{c}\text { Exploração mineral de calcário processado de modo descontrolado pode trazer efeitos danosos ao } \\
\text { ambiente. }\end{array}$ \\
\hline \multicolumn{2}{|c|}{$\begin{array}{l}\text { Cenários Tendenciais do } \\
\text { Contexto Socioambiental }\end{array}$} & $\begin{array}{l}\text { Com exploração mineral descontrolada e desmatamento, degradação ambiental com o gradual } \\
\text { empobrecimento do solo, comprometendo a renda de familias de atividades primárias. }\end{array}$ \\
\hline
\end{tabular}

Figura 8. Sistema ambiental Chapada sedimentar e subsistema. Fonte: Adaptado de Souza (1994).

\begin{tabular}{|c|c|c|}
\hline \multirow{2}{*}{\multicolumn{2}{|c|}{$\begin{array}{c}\text { SISTEMA AMBIENTAL } \\
\text { SUBSISTEMAS } \\
\text { AMBIENTAIS } \\
\end{array}$}} & 6 Maciço residual \\
\hline & & 6.1 Serra baixa de Ererê. \\
\hline \multicolumn{2}{|c|}{$\begin{array}{l}\text { Características } \\
\text { Naturais } \\
\text { Dominantes }\end{array}$} & $\begin{array}{l}\text { Situada a W da cidade de Itaiçaba, compondo uma estrutura elevada de três picos, sendo o mais alto } \\
\text { com cerca de } 140 \mathrm{~m} \text {, orientados na direção SE-NW, constituído basicamente por quartzitos } \\
\text { esbranquiçados a creme. Apresentam com formas dissecadas de topos aguçados exibindo rochas } \\
\text { nuas com feições de desagregação. Destaca-se sobre a topografia plana emergindo como elevação } \\
\text { residual constituindo maciço isolado. Têm arcabouço constituído por rochas do embasamento Pré- } \\
\text { Cambriano cuja complexidade possibilitou o trabalho expressivo da erosão diferencial marcada por } \\
\text { uma semi-aridez acentuada e uma morfogênese mecânica. O setor SW não há praticamente } \\
\text { diferença significativa com a morfogênese que vigora na depressão sertaneja. Nas vertentes os solos } \\
\text { têm pouca espessura, são pedregosos e é freqüente a ocorrência de blocos. A vegetação de caatinga } \\
\text { prepondera em toda a encosta. }\end{array}$ \\
\hline \multirow{2}{*}{ 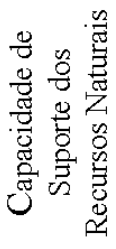 } & Potencialidades & Patrimônio paisagístico; atrativos turísticos; lazer e ecoturismo. \\
\hline & Limitações & Ocupação urbana; agricultura; extrativismo mineral e vegetal. \\
\hline \multicolumn{2}{|c|}{$\begin{array}{l}\text { Ecodinâmica e } \\
\text { Vulnerabilidade }\end{array}$} & Ambiente de transição com tendência à instabilidade; vulnerabilidade alta à ocupação \\
\hline \multicolumn{2}{|c|}{$\begin{array}{l}\text { Impactos e } \\
\text { Riscos de Ocupação }\end{array}$} & Riscos em função do relevo, degradação da cobertura vegetal e ocorrência de blocos. \\
\hline \multicolumn{2}{|c|}{$\begin{array}{c}\text { Cenários Tendenciais do } \\
\text { Contexto } \\
\text { Socioambiental }\end{array}$} & $\begin{array}{l}\text { Com a incidencia de atividades antrópicas resultando em perdas das características paisagísticas e } \\
\text { impactos ambientais que aceleram processos erosivos em função do relevo. }\end{array}$ \\
\hline
\end{tabular}

Figura 9. Sistema ambiental Maciço residual e subsistema. Fonte: Adaptado de Souza (1994). 


\section{Considerações finais}

A abordagem interdisciplinar possibilita de forma concisa aliar ciências sociais, econômicas e da terra com geotecnologias, mediante aplicação de técnicas adequadas, combinado às metodologias geossistêmicas, resultaram em subsídios ao ordenamento territorial. Promove assim a compreensão dos processos de degradação dos recursos naturais e possibilita direcionar medidas, com vista a manutenção dos ambientes naturais, melhoria da qualidade de vida de populações e equidade social.

A delimitação e caracterização dos sistemas ambientais, distinguindo sua capacidade de suporte e dinâmica ambiental contribuíram para o diagnóstico da dimensão socioambiental e prever cenários tendenciais. Esses dados associados com o apoio da dimensão econômico e políticoinstitucional permitirão subsidiar o ordenamento territorial. Parte-se do pressuposto que a busca da sustentabilidade do desenvolvimento em toda sua amplitude, há que considerar as suas dimensões estratégicas.

\section{Declaração de conflito de interesses}

Os autores declaram não haver conflito de interesses.

\section{Referências}

Anderson, L. O.; Shimabukuro, Y. E. Classificação espectro-temporal de formações vegetais. In: Rudorff, B. F. T.; Shimabukuro, Y. E; Ceballos, J. C. (Org.). O Sensor Modis e suas aplicações ambientais no Brasil. São José dos Campos, Parêntese, 2007.

Bacani, V. M. Geotecnologias aplicadas ao ordenamento físico-territorial da Bacia do Alto Rio Coxim-MS. São Paulo, USP, 2010. (Tese de doutorado).

Brasil. Ministério da Integração Nacional. Plano Nacional de Ordenação Territorial. 2005. Disponível em: <http://www.usp.br/fau/ docentes/depprojeto/c_deak/CD/5bd/2br/3plans/ 2006pnot/index.html>. Acesso em: 07 ago. 2014.
Batistella, M.; Moran, E. F. (Orgs.). Geoinformação e monitoramento ambiental na América Latina. São Paulo: Senac, 2008.

Bellen, H. M. Indicadores de sustentabilidade: uma análise comparativa. 2 ed. Rio de Janeiro: Ed. FGV, 2006.

Câmara, G.; Davis, C. Introdução: por que geoprocessamento. São José dos Campos: INPE, 2001.

Clementino, M. L. Ordenamento e planejamento territorial: a falta que faz o plano metropolitano, 2008. Disponível em: $<$ http://www.ub.edu/geocrit/-xcol/252.htm>.

Acesso em: 07 ago. 2014.

Filippini Alba, J. M.; Berny, V. M.; Costa, F. A. Geoprocessamento no contexto de empresas de pesquisa. Pelotas: Embrapa Clima Temperado, 2009. (Documentos 254).

Fitz, P. R. Geoprocessamento: sem complicação. São Paulo: Oficina de Texto, 2008.

Borja, J. F. C.; Uzeta, R. G. El ordenamiento territorial como eje de planeacion de proyectos de turismo sustentable. Ciencias Sociales Online, v. 4, n. 2, p. 101-118, 2007. Disponível em: <http://www.uvm.cl/csonline/2007_2/pdf/ cervantes-gomez.pdf $>$. Acesso em: 07 ago. 2014.

Longley, P. A.; Goodchild, M. F.; Maguire, D. J.; Rhind, D. W. Sistemas e Ciência da Informação Geográfica. 3 ed. Porto Alegre: Bookman, 2013.

Magalhães Júnior, A. P. Indicadores ambientais e recursos hídricos: realidade e perspectiva para o Brasil a partir de experiência francesa. Ed. Bertrand do Brasil: Rio de Janeiro, 2007.

Michel, M. L'aménagement regional em France: du territoire aux territoires. Paris: Mason, 1994.

Morgado, P.; Rocha, J. Modelação geográfica de indicadores de desenvolvimento sustentável: uma aplicação à Área Metropolitana de Lisboa. Lisboa: Centro de Estudos Geográficos, Universidade de Lisboa, 2008.

Peres, R. B.; Chiquito, E. A. Ordenamento territorial, meio ambiente e desenvolvimento regional. Revista Brasileira de Estudos Urbanos e Regionais, v. 14, n. 2, p. 71-86, $2012 . \quad$ Disponível em: $<$ http://unuhospedagem.com.br/revista/rbeur/ind ex.php/rbeur/article/view/4102/4000>. Acesso em: 07 ago. 2014. 
Oliveira, H. P. V. Avaliação dos indicadores do potencial turístico do Município de Itapipoca: subsídios para o desenvolvimento sustentável do turismo. Fortaleza: Programa Regional de Pós-graduação em Desenvolvimento e Meio Ambiente-PRODEMA, Universidade Federal do Ceará-UFC, 2009. (Dissertação de mestrado). Disponível em: <http://www.repositorio.ufc.br/bitstream/riufc/1 6233/1/2009_dis_hpvoliveira.pdf $>$. Acesso em: 07 ago. 2014.

Rodriguez, J. M. M.; Silva, E. V.; Cavalcanti, A. P. B. Geoecologia das paisagens: uma visão geossistêmica da análise ambiental. Editora UFC: Fortaleza, 2004.

Silva, A. B. Sistemas de Informações Georeferenciadas: conceitos e fundamentos. Campinas: Ed. UNICAMP, 2003.

Silva, J. X.; Zaidan, R. T. (Orgs.). Geoprocessamento \& Análise Ambiental: aplicações. Rio de Janeiro: Ed. Bertrand Brasil, 2004.

Souza, J. M. N; Oliveira, V. P. V. Análise ambiental: uma prática da interdisciplinaridade no ensino e na pesquisa. REDE - Revista
Eletrônica do Prodema, v. 7, n. 2, p. 42-59, $2011 . \quad$ Disponível em: $<$ http://www.revistarede.ufc.br/revista/index.ph p/rede/article/view/168/44>. Acesso em: 07 ago. 2014.

Souza, M. J. N. et al. Esboço do Zoneamento Geoambiental do Ceará. In: SEPLAN, FUNCEME. Projeto Áridas - Ceará. Grupo I Recurso Natural e Meio Ambiente. Fortaleza: SEPLAN, FUNCEME, 1994. v. 2. p.186-203.

Souza, M. J. N.; Meneleu Neto, J., Cruz, M. L. B.; Oliveira, V. P. V. Prognóstico da gestão ambiental da área de influência direta do Açude Castanhão. In: Medeiros, C. N.; Gomes, D. D. M.; Albuquerque, E. L. S.; Cruz, M. L. B. (Orgs.). Os recursos hídricos do Ceará: integração, gestão e potencialidades. Fortaleza: IPECE, 2011, p. 11-37.

Tricart, J. Ecodinâmica. Rio de Janeiro: FIBGE, SUPREN, 1977.

Venturi, L. A. B. Praticando geografia: técnicas de campo e laboratório. São Paulo: Oficina de Texto, 2005.

Informação da Licença: Este é um artigo Open Access distribuído sob os termos da Licença Creative Commons AtribuiçãoSemDerivações-SemDerivados, que permite o download do trabalho e o compartilhamento desde que seja atribuído o devido crédito, mas sem que possa ser alterado de nenhuma forma ou utilizá-los para fins comerciais. 